\title{
PEACEFUL WARRIOR (2006), DE DAN MILLMAN: PERSPECTIVAS EXISTENCIAIS NA CONTEMPORANEIDADE
}

\author{
Peaceful warrior (2006), by Dan Millman: contemporary existential perspectives
}

Peaceful warrior (2006), de Dan Millman: perspectivas existenciales en la contemporaneidad

\author{
Laís DuARTE DE MORAes \\ Listeux D'Jesus LuZia DE ARAúJo Rocha \\ BERTA LÚCIA NEves PONTE \\ José Clerton de Oliveira Martins
}

\begin{abstract}
Resumo: Este artigo tem como objetivo refletir acerca de valores e necessidades existenciais que atravessam o ser humano na atualidade de apressamentos, de consumismos exacerbados e da busca por prazeres efêmeros que vêm produzindo a sensação de vazio existencial. Tal vazio estabelece também a necessidade da busca de sentido de vida. Para este artigo, foi tomado como material de análise a narrativa do filme Peaceful Warrior (2006); optou-se por uma investigação qualitativa, na qual foi realizado um levantamento bibliográfico e se utilizou a Análise Categorial, a fim de definir as unidades de análise do filme, codificá-las e interpretá-las. O estudo aponta que a dedicação no desenvolvimento de um talento e no protagonismo das experiências subjetivas possibilitam transformações existenciais para o seguimento de um caminho vital com sentido no contexto contemporâneo.
\end{abstract}

Palavras-chave: Estilo de vida; Experiência de vida; Comportamento.

\begin{abstract}
This article aims to reflect on the values and existential needs that constitute the human being in the present times of hurries, exacerbated consumerism and the search for ephemeral pleasures that have been producing the sensation of existential emptiness. Such emptiness also establishes the need for the search for meaning of life. For this article, the narrative of the film Peaceful Warrior (2006) was taken as analysis material. This is a qualitative investigation, in which a bibliographic research was carried out and the Categorial Analysis was used. This process defined the film analysis units, which were coded and interpreted. The article concludes that the dedication to the development of a talent and the protagonism of the subjective experiences allow existential transformations for a vital path with sense in the contemporary context.
\end{abstract}

Keywords: Life style; Life change events; Behavior.

Resumen: Este artículo tiene como objetivo reflexionar acerca de valores y necesidades existenciales que atravesan el ser humano en la actualidad de apresuramientos, de consumismos exacerbados y de la búsqueda de placeres efímeros que vienen produciendo la sensación de vacío existencial. Tal vacío establece también la necesidad de la búsqueda de sentido de vida. Para este artículo, fue tomado como material de análisis la narrativa de la película Peaceful Warrior (2006); se optó por una investigación cualitativa, en la que se realizó un levantamiento bibliográfico y se utilizó el Análisis Categorial para definir las unidades de análisis de la película, codificarlas e interpretarlas. El estudio apunta que la dedicación para el desarrollo de un talento, y el protagonismo de las experiencias subjetivas posibilita transformaciones existenciales para el seguimiento de un camino vital con sentido en el contexto contemporáneo.

Palabras-clave: Estilo de vida; Experiencia de vida; Conducta.

\section{Introdução}

Somos levados a crer que em tempos de apressamento e consumismo exacerbado, a solidão e a fragilidade das relações afetivas se ampliam, produzindo a sensação de vazio existencial. O sujeito contemporâneo, em resposta a esse tempo acelerado e na tentativa de preencher o vazio, "mata o próprio tempo", entorpecendo-se de mais informação e superficialidades, tornando-o desprovido de sentido. Nessa lógica, o homem consome e é consumido na busca por prazeres que não passam do âmbito da efemeridade e do imediatismo. Constitui-se, portanto, um ciclo vicioso de insatisfação, prazer efêmero e, novamente, insatisfação (Oliveira \& Justo, 2010).
Frankl (2013) define como vazio existencial uma falta de sentido para a vida e as experiências que transformam o mundo interno do sujeito em um grande buraco, cheio de estranhezas e medos, ocasionando uma solidão desamparada. Solidão essa que vem levando o sujeito contemporâneo a buscar o prazer imediato e descartável.

O par "informação e opinião" são dois grandes representantes da contemporaneidade. Esta é marcada pelo apressamento e pela liquidez em muitos aspectos da vida, na qual os estímulos e acontecimentos passam demasiadamente depressa e nada nos toca, nada nos atravessa. A velocidade dos acontecimentos, as vivên- 
cias pontuais, a falta de consciência de um tempo para si, o excesso de informação e de opinião impedem que haja a conexão subjetiva e significativa entre nós e o que nos acontece (Larossa, 2016).

Em consequência disso, vivemos em uma superficialidade que não nos possibilita acessar a experiência, a possibilidade de que algo nos aconteça, atravesse, transforme ou toque. Isso não depende apenas do nosso saber, poder ou vontade. Sabemos que o sujeito da experiência se mostra tal como um território de passagem sensível e aberto para a travessia da existência, sendo algo que "pertence aos próprios fundamentos da vida, quando a vida treme, ou se quebre, ou desfalece; e em que a experiência, que não sabemos o que é, às vezes canta” (Larossa, 2016, p. 13).

O saber da experiência se apresenta na conexão entre o conhecimento e a dinâmica da existência humana, em que o sujeito da experiência se abre para vida, sendo por esta atravessado, de alto a baixo, conforme aponta Larossa (2016). Isso foi o que Sócrates tentou ensinar para Millman no filme Peaceful Warrior (2006), a arte de encontrar a si próprio e de acessar a sua interioridade.

Mediante a narrativa observada no filme Peaceful Warrior (2006), consideramos que o embate entre o vazio existencial e a busca por um sentido de vida são elementos-chave para a discussão deste estudo. Em um dos primeiros encontros com Millman, Sócrates pergunta para o jovem ginasta: você é feliz? Millman respondeu que não lhe faltava nada, pois possuía dinheiro, mulheres, muitos troféus, era um bom aluno na faculdade e tinha muitos amigos. Diante dessa resposta, observamos que a felicidade de Millman estava direcionada à heterocondicionamentos; isto é, ele significava aspectos subjetivos a fatores de referência sociocultural externa, como explicitado por Munné (1980).

Temos então como pressuposto que o modo de vida atual adotou hábitos e possibilidades de viver sem sentido, onde tudo perpassa, mas nada, de fato, transforma e atravessa o homem. Dessa forma, conjecturamos que, muitas vezes, os sujeitos contemporâneos não sabem mais o que é ou não é essencial para a vida, assim, quanto mais se mascara ao fugir de sua realidade subjetiva, do seu interior vazio, mais alimenta a angústia e o sofrimento, conforme aponta Lipovetsky (2005) e Frankl (2013).

Diante de tais reflexões, somos incitados a refletir sobre a subjetividade e a interioridade dos sujeitos contemporâneos que se constituem em tempos vazios de sentidos, permeada de vivências líquidas decorrentes de sujeitos que não acessam à experiência e consequentemente não se acessam, encontrando-se prisioneiros de sensações fugazes e de constante angústia. Nesse sentido, o homem contemporâneo, de acordo com Perls (2012), "parece haver perdido toda espontaneidade, toda capacidade de sentir e se expressar direta e criativamente" (p. 11).

Com base no exposto, refletindo acerca do homem a procura de si mesmo, mediante uma busca de sentido de vida, frente à reflexão que o filme sugere, emerge a seguinte indagação: como construir possibilidades de ser e existir com sentido no contexto da nossa sociedade contemporânea?

Neste parâmetro, vale ressaltar a importância de se refletir sobre o estilo de vida na contemporaneidade, na qual o sujeito busca, muitas vezes, prazer e satisfação fora de si a fim de saciar o vazio existencial sem pensar criticamente e conscientemente em quem ele é e o que quer. Assim, este estudo tem como objetivo refletir sobre as perspectivas existências contemporâneas, tomando como material de análise a narrativa do filme Peaceful Warrior (2006).

\section{Metodologia}

De acordo com a proposta deste artigo, o filme Peaceful Warrior (2006), traduzido em português como $O$ poder além da vida (2006), foi a nossa principal fonte de referência para as discussões aqui desenvolvidas. Dessa forma, procuramos abordá-lo por meio de uma metodologia adequada a fim de analisar e interpretar seu conteúdo.

Esse filme foi lançado em 2006 nos Estados Unidos sob a direção de Victor Salva, sendo considerado um material semiautobiográfico de Dan Millman, autor do livro O caminho do Guerreiro pacífico (Way of the peaceful warrior). O filme retrata uma história inspirada em fatos reais da vida de um jovem ginasta, que sonha em participar das Olimpíadas e ganhar medalha de ouro.

Millman, personagem principal do filme, possui uma rotina de treinamento bastante rígida e uma vida pessoal e social intensa, afirmando possuir tudo de que precisa: dinheiro, troféus, amigos e boas notas na faculdade.

Certo dia, Millman conheceu Sócrates (nome dado por Millman) em uma loja de conveniência. Desde esse encontro, Millman, auxiliado por Sócrates, passa por um período de transformações que o ajuda a elaborar um grave acidente de moto que inicialmente o impossibilitou de ser o que mais amava na vida: ginasta. Nesse processo, aos poucos, Sócrates foi estimulando Millman para que este pudesse experimentar o mundo de forma mais sensível.

Para analisar tal filme, recorremos ao método da Análise de Conteúdo, com o intuito de organizar este material audiovisual em dados objetivos passíveis de análise por categorias temáticas para, posteriormente, propormos relação entre tais dados e a teoria que sustenta nossas discussões.

A Análise de Conteúdo, segundo Bardin (2011), é um instrumento com uma variedade de procedimentos analíticos e adaptável ao campo das comunicações. A Análise de Conteúdo "aparece como um conjunto de técnicas de análise de comunicações que utiliza procedimentos sistemáticos e objetivos de descrição do conteúdo das mensagens” (Bardin, 2011 p. 44). Assim, a sistematização do conteúdo das mensagens possibilita a ampliação da expressão deste conteúdo, atingindo uma apreciação de significantes e significados.

Seguindo as fases propostas por Bardin (2011), or- 
ganizamos o método de análise do filme em três etapas:

1) "Pré-análise" - Demarcação e preparação do universo do material escolhido, ou seja, este período correspondeu a uma organização dos dados extraídos do filme, sistematizando ideias iniciais, identificando e explorando indicadores que poderiam fundamentar a interpretação/a ideia inicial e corresponder a proposta deste artigo;

2) "A exploração do material" - Momento que consistiu na realização da codificação e decomposição dos dados brutos, agregando-os em unidades que permitem uma descrição de características importantes do conteúdo a ser posteriormente analisado. No que tange ao estilo de codificação, as unidades de registro selecionadas para a análise de conteúdo se baseou em "núcleos de sentido" que constituem a comunicação; e o objeto ou referente que se trata de temas-eixos em torno dos quais o discurso se organiza, encontrando-se de acordo com o objetivo proposto.

Dentre as técnicas disponíveis pela Análise de Conteúdo para realizar o procedimento descrito acima, optamos pela Análise Categorial (AC), utilizando-se da criação de categorias de análise temática. A Análise Categorial (AC) "é um método de gavetas ou de rubricas significativas que permitem a classificação dos elementos de significação constitutivos da mensagem” (Bardin, 2011, p. 39). Assim, por meio desta técnica realizamos uma sistematização do fracionamento das unidades de registro do filme, classificando seus elementos de significação sobre o período de transformações do personagem principal em direção ao seu sentido de vida, a fim de definir as unidades de análise, codificá-las e interpretá-las.

3) "Tratamento dos resultados obtidos e interpretação" - Buscamos a interpretação dos resultados significativos das narrativas categorizadas a partir da fundamentação teórica utilizada no desenvolvimento deste artigo.

Cabe destacar que optamos por analisar a narrativa do filme em torno do personagem principal a fim de criar categorias de análise para posterior realização das articulações teóricas que se encontram no item seguinte.

\section{Dados e Análises}

Para melhor compreensão dos resultados e organização dos dados, com base no material analisado, elaboramos quadros em que descrevemos na coluna da esquerda os indicadores de conteúdo, passíveis de aplicação da análise de conteúdo observados no filme, que orientam as categorias - estas, localizadas na coluna da direita, criadas a fim de estabelecer vínculo entre os encaminhamentos das análises com os referenciais teóricos que embasaram este estudo. Tal procedimento está de acordo com o que delimitamos na explicação do método, a partir de Bardin (2011).

Tabela 1

Indicadores de Conteúdo/Primeira Categoria Criada e Respectivos Trechos do Filme

\begin{tabular}{|c|c|}
\hline INDICADORES DE CONTEÚDO & CATEGORIA \\
\hline $\begin{array}{l}\text { TRECHO 1A }(13: 25-13: 40) \text { "Mas o que felicidade tem a ver com isso? }(\ldots) \\
\text { O meu pai tem muito dinheiro, a faculdade é uma mamata, eu só tiro } 10 \text {, } \\
\text { tenho bons amigos, estou em ótima forma física e só durmo sozinho quando } \\
\text { eu realmente quero" (sic) }\end{array}$ & \\
\hline $\begin{array}{l}\text { Millman não conseguia dormir à noite e então passou a frequentar um posto } \\
\text { de conveniência. Neste local, conheceu Sócrates. Este aparentemente saltou } \\
\text { aproximadamente } 3,0 \mathrm{~m} \text { em um piscar de olhos, parando em cima da loja de } \\
\text { conveniência. Tal fato, deixou Millman intrigado e, então, perguntou a } \\
\text { Sócrates como conseguiu saltar tão alto. Este disse ao jovem que ele } \\
\text { precisaria saber sobre muitas coisas antes de compreender tal feito. Dessa } \\
\text { forma, o jovem, ostentando saber responder sobre tudo, pediu que Sócrates } \\
\text { o perguntasse o que quisesse. Sócrates, portanto, o indagou: "Você é feliz?" }\end{array}$ & $\begin{array}{l}\text { 1) VAZIO } \\
\text { EXISTENCIAL }\end{array}$ \\
\hline $\begin{array}{l}\text { TRECHO 1B (23:50 - 24:46) “Todo mundo diz o que deve fazer, o que faz } \\
\text { bem, ninguém quer que você encontre suas próprias respostas, querem que } \\
\text { acreditem nas deles (...) Eu quero que você pare de ouvir os outros e comece } \\
\text { a procurar respostas dentro de você (...) As pessoas tem medo do que há } \\
\text { dentro delas, mas é o único lugar aonde vão achar o que precisam. Porque } \\
\text { não consegue dormir? Será porque tarde da noite, quando tudo está em } \\
\text { silêncio e você está deitado na cama, sem ninguém ao lado, você fica com } \\
\text { medo, fica com medo porque você vai se sentindo vazio?” (sic) }\end{array}$ & \\
\hline $\begin{array}{l}\text { Sócrates falando para Millman quando este foi ao seu encontro na loja de } \\
\text { conveniência de madrugada. }\end{array}$ & \\
\hline
\end{tabular}


Esta categoria nos convoca a refletir sobre uma inversão de valores, uma vez que o personagem principal focou o desenvolvimento de si em fatores e expectativas externas e consequentemente se sentiu vazio e confuso sobre quem ele é e quem deveria ser. Nesta perspectiva, a busca por bem-estar, muitas vezes, é equiparada a heterocondicionamentos, conforme é indicado no trecho $1 \mathrm{~A}$.

A total ou extrema falta de sentido da vida é uma carência de consciência de um sentido pelo qual valesse a pena viver. $\mathrm{O}$ sujeito carente de sentido sente-se aprisionado "pela experiência de seu vazio interior de um vazio dentro de si mesmo; estão presos na situação que tenho chamado de vazio existencial” (Frankl, 2013, p. 130).

Millman sintetiza, em sua resposta no trecho 1A, uma possível expressão do modo de vida dos sujeitos contemporâneos; segundo Beriain (2008), a dinâmica da vida acelerada leva a negligenciar a qualidade da implicação subjetiva e de integração social em detrimento de uma corrida por especialização no mercado de trabalho, de busca de conhecimento, procurando consumir, possuir dinheiro e poder.

Em consequência disso, pode ocorrer um encurtamento da consciência do tempo presente que desemboca na transformação do tempo de contemplação, rico de sentido em um tempo vazio, fugaz, veloz e de abstração de sentido individual, tornando-se um tempo lógico, linear e centrado no relógio (Beriain, 1997).

Mediante o encurtamento da consciência do tempo presente, passamos a viver de forma inautêntica, no qual conferimos uma adesão incondicional ao presente imediato, linear e achatado. Perdemos então a tridimensionalidade do tempo: passado, presente e futuro. Achatados no presente imediato, o sujeito contemporâneo não acolhe o silêncio e a contemplação como possibilidades de se haver com o vazio existencial (Alonso-Fernandez, 1979; Heidegger, 2014).

Dentro desta lógica, pode-se afirmar que Millman, ao equiparar felicidade com dinheiro, sexo e ótima forma física, revela que o foco no desenvolvimento de si se apoia em fatores e expectativas externas a ele mesmo, estabelecendo assim uma adesão incondicional ao presente imediato e fugaz.

Em relação a essa inversão de valores, May (1976) afirma que o homem tem perdido, cada vez mais, o encantamento diante da vida e consequentemente se sente perdido e confuso sobre o que sente e o que é e o que deveria ser.

Complementando, Frankl (2013) relata que o vazio existencial é um fenômeno compreensível, uma vez que o homem com o passar do tempo foi perdendo seus instintos básicos que regiam seu comportamento e lhe garantia sua existência, além de estar perdendo as tradições que servem de apoio para o seu comportamento. Essas perdas fazem o homem deparar-se com opções e decisões, e diante delas, "às vezes, ele [o homem] não sabe sequer o que deseja fazer. Em vez disso, ele deseja fazer o que os outros fazem [conformismo], ou ele faz o que outras pessoas querem que ele faça [totalitarismo]" (Frankl, 2013, p. 131).

Na condição humana ocorrem momentos de paradas e/ou rupturas momentâneas onde podem surgir o vazio existencial e a falta de sentido da vida. Sabe-se que entrar em contato com essa realidade subjetiva pode causar sofrimento e deixa, muitas vezes, o sujeito sem saber o que fazer e como agir. Não foi diferente com Millman. No trecho 1B, Sócrates sugere que o fato de Millman apresentar insônia de madrugada é porque ele se sente sozinho e vazio, e sai de casa para fugir disso, para não ter que se haver com o vazio existencial inerente à condição humana.

O trecho $1 \mathrm{~B}$ pode fazer referência ao sujeito contemporâneo que não consegue ficar sozinho e busca agitação e barulho, pois não suporta o silêncio ou estar consigo mesmo, podendo tornar-se incapaz de ficar só, entregue à solidão e à reflexão de sua própria condição humana. Segundo Frankl (2013), o vazio se manifesta, muitas vezes, quando há um momento de silêncio e de solidão; quando a correria da semana atarefada cessa, o sujeito se depara com a falta de conteúdo de suas vidas.

"Onde há falta de significado pessoal, todas as espécies de diversão têm de criar um significado substituto, artificial” afirma Svendsen (2006, p. 28). O interesse pela vida que não é nossa, pela diversão, pelo lazer de entretenimento e pelo consumo podem ser sintomas de fuga do medo do vazio que nos cerca. "Quanto mais a vida individual se torna o centro do foco, mais forte se torna a insistência no significado em meio às trivialidades da vida cotidiana" (Svendsen, 2006, p. 28).

O comportamento de Millmam em relação a bebidas, sexo, dinheiro e busca de vivências/estímulos sensoriais pode ser considerado uma manifestação de fuga do seu vazio existencial. Inferimos, portanto, que Millman possivelmente não atribuía valores e significados às suas ações cotidianas, aspecto este imprescindível para definir um sujeito da experiência, sujeito este que investe tempo para refletir e sentir sua relação com o mundo (Larrosa, 2016).

Como tentativa de preencher os males da existência que o ser humano contemporâneo pode experimentar, o consumismo aparece enquanto fonte de satisfação e bem-estar, conforme anuncia Lipovetsky (2005). Já Frankl (2005) retrata que este ritmo de vida contemporâneo pode encobrir as frustações, o descontentamento e a não-realização do sentido existencial. Entretanto, quando o vazio existencial transparece sob tal estilo de vida contemporâneo, a satisfação psíquica é compensada pela satisfação imediata.

Assim, nesta perspectiva de ordem compensatória, Frankl (2013) define a "vontade de poder”. Esta é uma tentativa de buscar sentido por meio do enriquecimento material, em que o sujeito, ao entrar na lógica capitalista hodierna, assume um papel de consumidor passivo; e sua vida, portanto, gira em torno do ter e não do ser. Complementando, Pinheiro, Rhoden e Martins 
(2010) ressaltam que, na busca por bem-estar, a interioridade do homem acaba sendo preenchida pelas ofertas consumistas e mercadológicas que vendem felicidades ilusórias.

Ainda em busca de compensação, o homem contemporâneo pode se lançar, conforme Frankl (2013), na busca pela "vontade de prazer", em que o sujeito banaliza sentimentos e relações afetivas, entorpecendo-se em um mundo de aparências e de máscaras. Assim, a efemeridade das vivências tem como consequência um afrouxamento das relações sociais e afetivas, predominando o imediatismo e o consumo alienado, dentre outras opções desta sociedade tão cheia de alternativas, mas que ao mesmo tempo é vazia de sentido.

Nesta categoria percebemos que há diversas máscaras e disfarces sob os quais transparece o vazio existencial, na qual a vontade de sentido é frustrada. Com isso, muitas pessoas ignoram o que querem e também não possuem uma ideia nítida do que sentem, bem como lamentam a sua falta de autonomia em sua capacidade de tomada de decisões, sentindo-se impotentes, ocas e vazias por não conseguirem alinhar seu modo de viver de acordo com seus próprios desejos e necessidades. Quando não, há aqueles que possuem pouca convicção e senso de realidade de suas metas, tornando-se "apenas uma coleção de espelhos refletindo o que os outros esperam” (May, 1976, p. 14).

O ser humano sem perspectivas positivas e construtivas, isto é, "se não tiver evoluindo em direção a alguma coisa acaba por estagnar-se; as potencialidades transformam-se em morbidez e desespero e eventualmente em atividades destrutivas”, assinala May (1976, p. 22). Nesse sentido, a sensação de vazio advém da ideia de incapacidade de fazer algo em relação à sua própria vida e ao mundo.

Tabela 2

Indicadores de Conteúdo/Segunda Categoria Criada e Respectivos Trechos do Filme

\begin{tabular}{l} 
INDICADORES DE CONTEÚDO \\
\hline TRECHO 2A (31:36 - 34:01) "Eu esvaziei a sua mente (...) estava presente, \\
100\% envolvido na experiência (...) queremos que se desligue de sua mente \\
Dan (...) esvazie sua mente Dan, jogue fora o lixo que impede você de ver o \\
que realmente importa, este momento, aqui, agora. Quando você estiver no \\
aqui e agora vai ficar impressionado com o que pode fazer e como será bem \\
sucedido." (sic)
\end{tabular}

No primeiro dia de treinamento de Millman, para se tornar um guerreiro pacífico, Sócrates o jogou no riacho de um parque inesperadamente. Millman ficou sem entender o motivo dele ter feito isso. Posteriormente, ele declarou que não estava acontecendo nada ao seu redor. Sócrates então o segurou com as mãos, como se tivesse dado um choque em Millman. Dessa forma, o jovem começou a perceber o que estava acontecendo ao seu redor. As imagens aparecem em câmera lenta, dando foco no detalhe dos acontecimentos e os sons estavam intensificados.

TRECHO 2B (01:48:19 - 01:48:54) "É só se livrar dos pensamentos da sua cabeça que ficam te dizendo que não vai conseguir, quando está no aparelho, só o que importa é cada movimento que você faz (...) não tem nada a ver com a medalha, nem com que o seu pai pensa de você, nem com qualquer outra coisa. É somente aquele momento" (sic)

No dia da apresentação de Millman para às classificatórias das Olimpíadas, ele declarou ao seu colega ginasta o que aprendeu com Sócrates. Durante sua apresentação, desde o momento em que Millman passou o pó de gesso em suas mãos até o final de sua apresentação.

TRECHO 2C (01:53:00 - 1:53:20)

- Onde você está, Dan?

- Aqui.

- Que horas são?

- Agora.

- O que você é?

- Este momento.

Ao final da apresentação de Millman para as classificatórias das Olimpíadas, quando Millman ainda estava em movimento nas argolas, aconteceu esse possível devaneio em forma de conversa entre Sócrates e Millman. Assim é a cena final do filme.

\section{CATEGORIA}

\section{2) APROPRIAÇÃO}

DO TEMPO

PRESENTE 
Esta segunda categoria diz respeito à apropriação do tempo presente, pois o protagonista reaprendeu a acessar a experiência, abrindo-se para as possibilidades de restituir sentidos diante de sua vida, como nos retrata o trecho 2A. Assim, Millman vai se apropriando da capacidade de viver no tempo presente que exige um alto grau de consciência, uma vez que só é possível interrogar sobre si e desvelar um sentido de vida no tempo presente (Reis, 2005). Sobre experiência, apropriamo-nos do conceito retratado por Larossa (2016):

Experiência é o que nos passa, o que nos acontece, o que nos toca. Não o que se passa, não o que acontece, ou o que toca. A cada dia se passam muitas coisas, porém, ao mesmo tempo, quase nada nos acontece. Dir-se-ia que tudo o que se passa está organizado para que nada nos aconteça. (...) Nunca se passaram tantas coisas, mas a experiência é cada vez mais rara (Larrosa, 2016, p. 18).

A possibilidade de se ter experiência requer uma interrupção, requer parar para pensar, para olhar, para escutar, dar-nos tempo e espaço para ouvir aos outros e a nós mesmos (Larossa, 2016). Tal como descrito no trecho 2A, Millman, ao ser jogado no riacho, experiencia uma expansão dos sentidos e apropria-se do tempo presente, restituindo assim uma disposição para os sentidos.

O fazer, sentir e pensar perpassam a experiência preenchendo de sentidos o viver. E as experiências se desenrolam no tempo, por isso que as mesmas ficam comprometidas pelo fato do tempo na contemporaneidade exprimir-se escasso diante das sobrecargas de demandas e aceleração dos ritmos vitais. É tão essencial, por isso, as decisões de investimento ou implicação temporal do sujeito, já que a qualidade da existência vai sendo delineada pelo conteúdo das experiências. Claro que a decisão de investimento temporal não conta exclusivamente com o sujeito, o qual é atravessado por meandros culturais e sociais. Existe, contudo, um espaço para a subjetividade humana nas decisões temporais: o sujeito tem a possibilidade de certa autonomia nesse quesito (Csikszentmihalyi, 2007).

Focalizar a atenção em uma dada tarefa é necessário para que o sujeito desenvolva operações mentais em profundidade. Sem foco, a consciência apresenta-se em estado de caos, configurando-se em uma desordem informativa de pensamentos aleatórios e dispersos; ocasião em que desejos, intenções e pensamentos conflitivos requerem a atenção da consciência. Por isso, é imprescindível a aprendizagem da capacidade de concentração para que o sujeito adquira controle sobre a energia psíquica como alimento essencial para o processo de pensamento (Csikszentmihalyi, 2007).

$\mathrm{O}$ que Sócrates quer ensinar a Millman nos trechos $2 \mathrm{~A}$ e 2B é que o jovem ginasta suspenda os pensamentos e julgamentos para focalizar sua atenção ao momento presente com o intuito de transformar o seu fazer, pensar e sentir em uma possibilidade de experiência.

O sujeito da experiência se encontra disponível para si, para o mundo, para os acontecimentos que lhe tocam e lhe formam, ou seja, está aberto para sua própria transformação. Já o saber da experiência se dá na relação entre conhecimento e vida humana, no modo como vamos desvelando sentido ou o não-sentido ao que nos acontece e respondendo ao que nos acontece ao longo da vida. Por isso, o saber da experiência é um saber particular, singular, subjetivo e pessoal. A experiência e o saber da experiência são o que nos permite apropriar-se de nossa própria vida (Larossa, 2016).

Nesse aspecto, o sujeito da experiência é um sujeito passivo, um sujeito que para e se deixa atravessar, sendo tomado pela experiência que o tira de um lugar (de si mesmo) e o leva a outro lugar (para além de si mesmo). Tal abertura para a experiência e consequentemente conquista do tempo presente foi o que Sócrates tentou ensinar para Millman no decorrer do filme.

O estar inteiro, presente e dedicado ao momento que se vive, é, na verdade, uma "interrupção no tempo" para que algo nos toque a fim de acessarmos a possibilidade de ser sujeito da experiência, tal como pode ser percebido no trecho $2 \mathrm{C}$.

O conceito de experiência é estruturante do ser humano, uma vez que é uma forma de valorização da presentificação, possibilitando o aprendizado e o crescimento como ser humano, uma vez que ele desvela sentido ao que lhe acontece e interpreta o mundo em que vive (Frankl, 2005).

Aprender a viver a realidade do momento presente é ao mesmo tempo construir um bom relacionamento com o tempo, uma vez que o presente é o momento atual que dispomos e o passado e o futuro só podem ter significações quando se fazem refletir no momento presente. Viver no tempo presente requer consciência de si mesmo, possibilitando ao sujeito apropriar-se de si, indagar sobre quem ele é, sobre sua vida e sobre o mundo, acessando o passado e projetando-se para o futuro. Defrontar o momento presente com coragem e proveito pode ser uma forma ótima de garantir o futuro, uma vez que este nasce do presente e dele se constitui (May, 1976; Reis, 2005).

Projetar-se para o futuro, visando evoluir no presente, é a capacidade do ser humano em orientar sua vida pela sabedoria. $\mathrm{O}$ trecho $2 \mathrm{C}$ revela a apropriação e a valorização do tempo presente vivenciado por Millman. Referimo-nos à capacidade "da qual o homem é ao mesmo tempo herdeiro dos tempos passados e depositário da posterioridade. (...) Essa aptidão em olhar para a frente e para trás faz parte da capacidade humana para ter consciência de si mesmo” (May, 1976, p. 213).

Mediante isso, a questão do sentido da vida só pode ser vivenciada na manifestação do homem (ser) dotado de consciência que acompanha nossa ação no mundo - nosso exercício de ação no mundo - no horizonte do tempo presente. Segundo Reis (2005), a ques- 
tão do sentido do ser só pode ser dita e pensada nos diversos modos de suas manifestações no horizonte do tempo, mediante os limites de sua existência finita.

A apropriação do tempo presente, segundo Alonso-Fernandez (1979), propicia uma existência autêntica. Nessa existência, temos uma sucessão de momentos, cada um dos quais integra uma síntese do passado, presente e futuro. Assim, colocamo-nos no horizonte do tempo, onde nos revelamos como sujeitos projetados para o futuro.

Nesse sentido, a apropriação do tempo presente encaminha o sujeito da experiência a uma consciência de si, imprescindível para o desvelar do sentido de seu existir como vamos relatar na próxima categoria.

Tabela 3

Indicadores de Conteúdo/Terceira Categoria Criada e Respectivos Trechos do Filme

\begin{tabular}{l} 
INDICADORES DE CONTEÚDO \\
\hline TRECHO 3A (01:07:04 - 01:09:24) \\
- O que você quer? Ninguém vai me impedir, por isso vai embora! \\
- Eu não estou aqui para impedir nada \\
- Acha que não consigo? Porque eu não tenho medo de nada. Olha só para você, \\
vivendo com medo de cair, por mim caí! Não é como se estivesse desistindo de nada \\
mesmo, nada que já não tenha perdido, fala pra mim, você está se agarrando a que? \\
- É você, não é? Eu tenho que me livrar de você. \\
-Sabe o que está fazendo? \\
- Não. \\
- Não sabe quem você é... sem mim? \\
- Não. \\
- Então o que você está fazendo?
\end{tabular}

Em sonho, Millman fala consigo mesmo após passar por períodos de sofrimentos e dificuldades, como o descrédito médico quanto a possibilidade de voltar a praticar ginástica e a negativa de seu treinador de orientá-lo. Em sonho Millman encontra a si mesmo em uma torre do relógio, culminando por fim em deixar cair do alto da torre a si mesmo.

TRECHO 3B (1:11:26 - 1:12:50)

- Eu não sei o que fazer agora.

- A primeira descoberta de um guerreiro.

- Qual?

- Não saber (...).

- O que fazer quando não se pode fazer aquilo para o qual nasceu?

- Tudo tem um propósito, Dan. Até isso. E depende de você encontrá-lo.

Primeiro encontro com Sócrates logo após o encontro consigo na torre do relógio. Dan estava triste.

TRECHO 3C (01:24:17 - 01:24:33) "Não valorizei o meu talento, não cuidei da minha vida, estou com medo, mas acho que me livrei do passado e sinto que é coisa certa a fazer (...) Quero conseguir fazer isto, acho que estou pronto (...) (pronto) para dedicar a minha vida a um propósito maior" (sic)

Este momento Millman já estava mais consciente de si, de suas escolhas e ações após declarar isso a Sócrates, este sugeriu que o jovem deveria continuar na ginástica, ressaltando que um guerreiro não procurava a perfeição, nem a vitória ou a invulnerabilidade e que o guerreiro acha o amor no que faz. Sócrates afirma que o acidente foi o treinamento de Millman e que na vida pode-se escolher o que quiser ser e assim não deveria pensar no futuro porque segundo Sócrates: "Não existe início, nem chegada, só o caminho" A seguir, Sócrates mostra as argolas que montou para Millman e assim ele retomou os treinamentos.

TRECHO 3D (01:35:19 - 01:36:06) "Eu estava pronto para desistir de tudo, mas você ficou parado ali e me disse que queria que eu treinasse de novo (...) eu adoro fazer isso (...) sonhar em poder estar lá e vencer a competição, fazer o que eu sempre achei que tivesse nascido para fazer, antes de andar de bicicleta eu já estava em cima de um trampolim porque eu adorava fazer isso, era a única coisa que eu tinha certeza de amar" (sic)

Logo após saber da notícia de que não foi aceito pelo comitê olímpico para participar da competição, Dan desabafou com Sócrates. Este ressaltou ao jovem que o ouro não era importante e que era preciso aceitar o fato de que não se pode ter controle sobre o que acontece, como o fato de não poder ir ou não às olimpíadas.

CATEGORIA

3) DESVELANDO

SENTIDO 
Esta categoria corresponde à valorização do vivido em que o personagem principal passou a se dedicar no desenvolvimento de seu talento, descobrindo, assim, as possibilidades de realização de sua existência no tempo presente, recuperando o enigma de si.

Desde a Antiguidade até os dias de hoje, o homem vem enfrentando o desafio de se interrogar sobre o sentido de sua vida a ser desvelado em seu percurso existencial (Frankl, 2013; Reis, 2005). Os gregos buscavam as respostas de suas angústias e dúvidas no Oráculo de Delfos, onde encontrava-se uma esfinge, monstro mitológico que significa "apertar a garganta até sufocar ou asfixiar”. Seus enigmas poderiam ser resumidos em tais perguntas: "Quem sou eu e o que faço aqui? De onde venho? Para onde vou?" (Salis, 2011). Perguntas que ainda hoje são essenciais para a existência humana.

Achamos que não estamos no mundo à toa, que tanto o passado como o futuro envolvem um significado que nos cabe descobrir e entender. Ninguém se conforma em ser apenas um amontoado de reações químicas e orgânicas sem sentido, que apenas segue as leis da biologia. Sentimos que há algo maior, espiritual, que habita em nós, e queremos encontrar um caminho para esse mistério que culminará com nossa morte física, mas não espiritual (Salis, 2011, p. 18).

A busca de sentido da vida e os enigmas da esfinge se apresentaram para Millman em meio a uma crise existencial. $\mathrm{O}$ ginasta sofreu um acidente de moto, recebendo o descrédito médico quanto à possibilidade de voltar a praticar ginástica e a negativa de seu treinador de orientá-lo. Após esse momento, Millman sonha tendo um diálogo consigo, assemelhando-se a um encontro com a esfinge. Ao se questionar sobre quem ele é e o que pensa que está fazendo consigo e com sua vida, Millman se deixa cair do alto da torre, isto é, aspectos de si que negavam a mudança que havia ocorrido em sua vida, após o acidente, tal como é retratado no trecho 3A.

Buscar possibilidades face a realidade para nossa trajetória de vida é o que a esfinge exigia para não sermos devorados pela angústia de não sabermos sobre si e pelo medo das incertezas e do desconhecimento sobre o que viemos fazer aqui. Segundo o trecho 3B, a primeira descoberta de um "guerreiro" é não saber o que fazer agora, isto é, deparar-se com a angústia de não saber. Tal angústia é representada por um aperto, uma espécie de estreitamento no qual o sujeito se depara com a necessidade de fazer escolhas mediante as suas condições e possibilidades reais de vida (Dantas, 2011).

Percebemos, portanto, que no trecho 3A Millman dá início ao seu processo de autoconhecimento ao confrontar-se consigo mesmo, enquanto no trecho 3B encontra-se inquieto e angustiado diante da busca por respostas sobre o seu propósito de vida, descobrindo assim a possibilidade de desvelar sentidos e significados mediante o vazio que lhe desassossega, retratado, então, pelo trecho 3C. Assim, Millman, a partir da apropriação das suas possibilidades de realizações existenciais mediante o presente, ao prospectar-se para o futuro, conseguiu ampliar sua consciência em relação ao seu sentido de vida em potencial e responsabilizar-se por sua vida que o impulsionou para a dedicação de seus talentos, sonhos e projetos futuros.

A necessidade humana de encontrar sentido na experiência vivida é, portanto, o que Frankl (2013) fundamenta como "vontade de sentido": uma busca do sujeito por um sentido como uma motivação primária em sua vida. Sentido este exclusivo e específico que só pode ser cumprido por aquela determinada pessoa, como se todo homem possuísse um sentido em potencial, de sua existência e de cada situação, a ser realizado. É um sentido específico da vida de uma pessoa em um dado momento.

A ontologia dimensional frankliana concebe o homem como ser tridimensional por abranger as dimensões somática, psíquica e noética (ou espiritual). A dimensão noética, exclusivamente humana, corresponde à tomada de posição livre em face das condições corporais e de existência psíquica perceptíveis nas decisões pessoais da vontade, intencionalidade, interesse prático e artístico, pensamento criativo, religiosidade, consciência moral e compreensão de valor (Lukas, 1989).

A busca de sentido ancora-se por meio da estimulação da consciência do ser e de sua reponsabilidade, podendo "causar tensão interior em vez de equilíbrio interior. Entretanto, justamente essa tensão é um pré-requisito indispensável para a saúde mental” (Lukas, 1989, p. 129) e para a transcendência existencial, no horizonte de seu sentido a realizar tal como afirma Frankl (2013). Para este mesmo autor, tal tensão corresponde “àquilo que já se alcançou e aquilo que ainda se deveria alcançar, ou o hiato entre o que se é e o que se deveria vir a ser" (Frankl, 2013, p. 129).

Sob esse ponto de vista, essa tensão, esse hiato entre o que se é e o que se deveria ser, pode ser percebida no trecho $3 \mathrm{C}$, uma vez que Millman recapitula o passado afirmando que não valorizou seu talento; com o auxílio de Sócrates, aos poucos, passa a ter consciência da responsabilidade por sua vida, afirmando a Millman que possui a liberdade de escolher o que quer vir a ser. Assim, nesse processo, o acidente foi percebido como um treinamento, conforme colocado por Sócrates no trecho 3C, um marco de balanço de vida no qual Millman retornou ao passado no presente, ressignificando-o e ao mesmo tempo transcendendo-se motivado pelo sentido de ser que está por vir.

Vale ressaltarmos, portanto, que o homem possui liberdade de escolha, tendo a oportunidade de escolher aquilo que quer ser - o que há de ser - e com isso realiza o seu sentido. Por meio da liberdade e responsabilização de suas escolhas é que o sujeito pode desenvolver os seus valores e significados. Responder por essas escolhas é ter responsabilidades e compromissos por elas. Quando o sujeito se dá conta - toma consciência - de sua liberdade e age responsavelmente pode 
realizar-se, motivado pelo que considera os sentidos de sua vida (Frankl, 2005).

O sentido da vida é único e pessoal, sempre se modifica, mas nunca deixa de existir. Segundo a logoterapia, pode-se descobrir esse sentido sob diferentes formas: “a) criando um trabalho ou praticando um ato; b) experimentando algo ou encontrando alguém; c) pela atitude que tomamos em relação ao sofrimento inevitável”, de acordo com Frankl (2013, p. 135). Essa segunda maneira pode ser experimentando algo como a bondade, a verdade e a beleza, experimentando a natureza, a cultura ou amando outro ser humano.

Como apresentado no trecho 3D, para Millman, o sentido da sua vida estava atrelado à sua prática de ginástica. Por meio do seu talento, Millman encontrou uma forma de criar-se e recriar-se em meio às mudanças de sua vida. Essa busca por esse sentido só se dá na relação do homem no mundo, é o desenrolar da existência que vai lhe propor a perguntar sobre qual o sentido de seu ser com o objetivo de despertar de si para si em relação ao mundo. O homem já se encontra lançado no mundo, desde sempre, e é este mesmo mundo o lugar para o desvelamento das verdades desse ente (Heidegger, 2014).

Semelhante ao caminho percorrido por Millman, encontrar possibilidades novas de existir para si próprio nas tradições clássicas era a realização do caminho de Hermes de cada um. Tal caminho significa "a coragem de cada um entrar dentro de si e descobrir quais as possibilidades que tinha para realizar sua existência aqui. Faziam isso através da busca, descoberta e realização de talentos", conforme Salis (2011, p. 52). Tal caminho possibilita afastar-se da ignorância e buscar a descoberta de si por meio da revelação de suas potencialidades e talentos que orientavam a vida.

\section{Considerações Finais}

As categorias e discussões abordadas neste estudo, apesar de terem sido analisadas separadamente, possuem conexões intrínsecas. Conforme o objetivo proposto, nas categorias abordamos encaminhamentos acerca de modos de ser e existir na nossa sociedade contemporânea à luz do filme $O$ poder além da vida.

Diante das análises e discussões, percebemos que não é possível escapar do que é essencial ao humano: da nossa vontade de sentido, dos nossos sofrimentos e das nossas angústias. O ser humano, assim como no caso de Millman, sente, frequentemente, medo de entrar em contato consigo mesmo, e assim foge de si mesmo, querendo tamponar o sofrimento e a angústia com o auxílio de artifícios compensatórios (vontade de poder e de prazer), tão presentes na nossa sociedade contemporânea, como foi discutido na primeira categoria. Notamos o quanto Millman tentou fugir de sua vontade de sentido, sofrimentos, medos e angústias diante de seu desconhecimento sobre o que viemos fazer aqui, de seu propósito de vida, diante dos riscos e vulnerabilidades do não saber, das incertezas. Assim, através de artifícios compensatórios tão presentes da nossa sociedade con- temporânea, como foi discutido na primeira categoria, quis tentar tamponar o sofrimento e a angústia.

Nesta lógica, o homem encontra-se perdido e confuso sobre si mesmo - quem é, o que quer e quem deveria ser -, tornando-se, muitas vezes, incapaz de tomar consciência de si e de suas próprias potencialidades, assim como de sentir e agir espontaneamente e criativamente. Tal sujeito contemporâneo encontra-se, muitas vezes, quase que descolado subjetivamente de si mesmo e do mundo. Nesse contexto, acaba por expressar uma vivência inautêntica.

A conexão subjetiva do homem com o mundo se faz imprescindível para se constituir um sujeito da experiência, que, pela valorização do tempo presente, pode transformar um momento fecundo, sendo motivado por sua vontade de sentido. Nesse processo de valorização do tempo presente, o sujeito se projeta, tendo em vista o que quer ser - o que está por vir-a-ser -, e ao mesmo tempo transcende a si mesmo, conforme abordamos na segunda e terceira categoria. Aqui nos deparamos com uma vivência autêntica, na qual o tempo é o próprio sujeito.

Por meio da tomada de consciência do tempo presente e de si - ser sujeito da experiência -, o homem pode desvelar sentido para seu existir. Tal tomada de consciência é possível mediante a valorização de vivências que o atravessem e que o permitam perceber uma congruência entre suas emoções, intenções e pensamentos, isto é, a harmonia entre coração, vontade e mente. Dessa forma, conforme exploramos na terceira categoria, o sujeito toma consciência de sua liberdade de escolha e se responsabiliza sobre ela, como possibilidade de conduzir o presente, tendo em vista um futuro almejado.

Dessa forma, conjecturamos que as possibilidades de realização de nossa existência e o desvelamento do sentido de vida equivalem ao redescobrimento do encantamento, da contemplação e da satisfação de se relacionar com a vida, da alegria de viver, apreciando a verdadeira liberdade de ser.

Diante do exposto, acreditamos ainda que o ser humano possui potencialidades e capacidades próprias que só podem ser desveladas por si próprio sendo no mundo, em sua relação de existir no mundo. No caso do filme, Millman, por meio do seu talento de ginasta, descobriu uma abertura de acesso ao seu ser. Cabe, portanto, a cada um de nós, através do autoconhecimento, desvendar nossa porta de acesso para a transcendência de nós mesmos e construir um caminho vital com sentido. Vale ressaltar ainda que o filme escolhido para a realização deste estudo é uma obra baseada em uma história real vivida por Dan Millman, e, embora o cinema seja uma ferramenta expressiva para destacar elementos cotidianos, não se tem aqui o intuito de abranger toda a realidade. 


\section{Referências}

Alonso-Fernandez, F. (1979). Fundamentos de la psiquiatria actual. Madrid: Paz Montalvo.

Bardin, L. (2011). Análise de Conteúdo. São Paulo: Edições 70.

Beriain, J. (1997). El Triunfo del Tiempo: Representacines Culturalis de Temporalidades Sociais. Revista Política y Sociedad, 25, 101-118.

Beriain, J. (2008). Aceleración y Tirania del Presente: la metamorfosis em las estructuras temporales de la modernidad. Barcelona: Anthropos Editorial.

Csikszentmihalyi, M. (2007). Aprender a fluir. Barcelona: Editorial Kairós.

Dantas, J. B. (2011). Angústia e Existência na Contemporaneidade. Rio de Janeiro: Rubio.

Frankl, V. E. (2005). Um sentido para a vida: psicoterapia e humanismo. São Paulo: Ideias \& Letras.

Frankl, V. E. (2012). Logoterapia e análise existencial: textos de seis décadas. Rio de Janeiro: Forense Universitária.

Frankl, V. E. (2013). Em busca de sentido. Petrópolis: Vozes.

Heidegger, M. (2014). Ser e tempo. Petrópolis: Vozes.

Larossa, J. (2016). Tremores: escritos sobre experiência. Belo Horizonte: Autêntica.

Lipovetsky, G. (2005). A era do vazio: ensaios sobre o individualismo contemporâneo. Barueri: Manole.

Lukas, E. (1989). Logoterapia: a força desafiadora do espírito - métodos de logoterapia. São Paulo: Edições Loyola.

May, R. (1976). O homem à procura de si mesmo. Petrópolis: Vozes.

Munné, F. (1980). Psicosociologia del tiempo libre. Ciudad de Mexico: Trilhas.

Oliveira, A. A. A., \& Justo, J. S. (2010). Expressões do tédio na contemporaneidade: uma análise do romance "Encontro Marcado", de Fernando Sabino. Revista de Psicologia da Unesp, 9(1), 45-57.

Perls, F. (2012). A abordagem gestáltica e a testemunha ocular da terapia. Rio de Janeiro: LTC.

Pinheiro, K. F., Rhoden, I., \& Martins, J. C. de O. (2010). A experiência do ócio na sociedade hipermoderna. Mal-Estar e Subjetividade, 10(4), 1131-1146.
Reis, J. (2005). O tempo em Heidegger. Revista Filosófica de Coimbra, 14(28), 369-414.

Salis, V. D. (2011). Mitologia Viva: aprendendo com os deuses a arte de viver e amar. São Paulo: Nova Alexandria.

Svendsen, L. (2006). A filosofia do tédio. Rio de Janeiro: Jorge Zahar.

Laís Duarte de Moraes (orcid.org/0000-0003-07902106). Universidade do Minho.Email:laishinodalp@ gmail.com

Lisieux D'Jesus Luzia de Araújo Rocha (orcid. org/0000-0002-9869-3866). Faculdade Católica de Fortaleza. Email: rochalisieux@gmail.com

Berta Lúcia Neves Ponte (orcid.org/000-00028889-2458). Universidade de Fortaleza. Endereço: Rua Carlos Vasconcelos, 146, apto. 1300. Bairro Meireles. Fortaleza/CE, Brasil. CEP: 60115-170. Email: bertaponte@hotmail.com

José Clerton de Oliveira Martins (orcid.org/00000002-8229-0915). Universidade de Fortaleza. Email: jclertonmartins@gmail.com

Recebido em 25.10.2018

Aceito em 18.10.2019 